\title{
A randomised trial: effects of different anesthesia methods on early perioperative pain sensitivity and cellular immune function in patients undergoing radical mastectomy
}

\author{
Jiacen $\mathrm{Li}^{1,2 \#}$, Qiang Lyu ${ }^{1,2 \#}$, Wenjie Su${ }^{1,2}$, Meiting $\mathrm{Li}^{1,2}$, Yu Du ${ }^{1,2}$, Yunxia Hu${ }^{1,2}$ \\ ${ }^{1}$ Department of Anesthesiology, Sichuan Provincial People's Hospital, University of Electronic Science and Technology of China, Chengdu, China; \\ ${ }^{2}$ Chinese Academy of Sciences Sichuan Translational Medicine Research Hospital, Chengdu, China \\ Contributions: (I) Conception and design: J Li, Q Lyu; (II) Administrative support: Y Du, Y Hu; (III) Provision of study materials or patients: All \\ authors; (IV) Collection and assembly of data: All authors; (V) Data analysis and interpretation: All authors; (VI) Manuscript writing: All authors; (VII) \\ Final approval of manuscript: All authors. \\ "These authors contributed equally to this work. \\ Correspondence to: Yu Du; Yunxia Hu. Department of Anesthesiology, 32 West Road Section2, First Ring Road, Chengdu, China. \\ Email: duyu2011@163.com; huyunxia61@163.com.
}

Background: This study sought to investigate the effects of transversus thoracic muscle plane-pectoral nerves (TTP-PECS) block combined with propofol anesthesia on early perioperative pain sensitivity and cellular immune function in patients undergoing radical mastectomy.

Methods: A total of 115 patients who underwent radical mastectomy for breast cancer at our hospital from January 2019 to January 2021 were selected as the study subjects. The patients were allocated to the control group $(n=57)$ or observation group $(n=58)$ using a random number method. The control group was given simple general anesthesia, and the observation group was given TTP-PECS block combined with propofol anesthesia. The recovery time, pain [visual analogue scoring (VAS)] scores, and incidences of adverse reactions were compared between the 2 groups. Hemodynamic indicators [i.e., heart rate (HR), mean arterial pressure (MAP)], stress indicators [i.e., blood glucose (GLU), epinephrine (E), cortisol (Cor)], and the cellular immune function ofthe2 groups before anesthesia (T0), at the end of operation (T1), 1day after operation (T2) and 3 days after operation (T3) were recorded.

Results: The spontaneous respiration recovery time, time to full wakefulness and the extubation time of the observation group were shorter than those of the control group $(\mathrm{P}<0.05)$. The observation group had lower VAS scores than the control group at 2, 8, 12, and $24 \mathrm{~h}$ after operation $(\mathrm{P}<0.05)$. The levels of MAP, HR, GLU, E and Cor in the observation group at T1, T2, and T3 were lower than those in the control group $(\mathrm{P}<0.05)$. Compared to the control group, the observation group had increased cluster of differentiation $(\mathrm{CD}) 3^{+}, \mathrm{CD}^{+}$, and $\mathrm{CD}^{+} / \mathrm{CD}^{+}$cells $(\mathrm{P}<0.05)$, but there were no significant differences in $\mathrm{CD}^{+}$and natural killer $(\mathrm{NK})$ cells between the 2 groups $(\mathrm{P}>0.05)$. The incidence of adverse reactions in the observation group was lower than that in the control group $(8.62 \%$ vs. $24.56 \%)(\mathrm{P}<0.05)$.

Conclusions: TTP-PECS block combined with propofol anesthesia can relieve pain, shorten the recovery time, stabilize the hemodynamic level, and alleviate the stress responses of patients undergoing radical mastectomy with a slight suppression of cellular immune function and high safety.

Trial registration: Chinese Clinical Trial Registration Center ChiCTR2100048438.

Keywords: Radical mastectomy; transversus thoracic muscle plane-pectoral nerves block (TTP-PECS block); propofol; pain sensitivity; cellular immune function

Submitted May 12, 2021. Accepted for publication Jul 19, 2021.

doi: $10.21037 / g s-21-343$

View this article at: https://dx.doi.org/10.21037/gs-21-343 


\section{Introduction}

Breast cancer is a common invasive cancer in women, and is the most common cancer among women (1). Radical mastectomy is a common surgical procedure for the treatment of breast cancer. The operation range is wide and traumatic, which can cause chronic or acute pain. Cancer patients have poor physical fitness due to long-term energy consumption. Inadequate perioperative analgesia can lead to body stress responses, hemodynamic fluctuations, and immune dysfunction, which are not conducive to postoperative recovery; thus, perioperative analgesia is very important $(2,3)$. In the past, general anesthesia was often used, but the transmission of surgical trauma to the central nervous system could not be completely blocked, and it was difficult to meet the ideal anesthesia requirements (4). In recent years, the studies have shown that transversus thoracic muscle plane-pectoral nerves (TTP-PECS) block has a significant anesthesia effect on radical mastectomy and can stabilize hemodynamics $(5,6)$. PECS block can provide anesthesia in the region of the lateral breast, blocking the cutaneous branches of the intercostal brachial nerve, the lateral intercostal nerve, the long thoracic nerve, and the thoracic dorsal nerve; however, it cannot block the medial breast region. However, TTP block can block the inner region of the breast. Thus, TTP-PECS block has a better analgesic effect $(7,8)$. To date, little research has been conducted on TTP-PECS block combined with propofol anesthesia in patients undergoing radical mastectomy. This study further analyzed the anesthesia effects of TTP-PECS block during radical mastectomy. We present the following article in accordance with the CONSORT reporting checklist (available at https://dx.doi.org/10.21037/gs-21$343)$.

\section{Methods}

\section{General information}

A total of 115 patients, who underwent radical mastectomy for breast cancer at our hospital from January 2019 to January 2021, were selected as the research subjects. All patients agreed to participate in this study and signed an informed consent form. The study was conducted in accordance with the Declaration of Helsinki (as revised in 2013). This study was approved by the Sichuan Provincial People's Hospital, University of Electronic Science and Technology of China (No. 20181205). To be eligible to participate in this study, patients had to meet the following inclusion criteria: (I) have undergone a radical mastectomy for breast cancer (according to the American Association of Anesthesiologists (ASA), the surgery is divided into grades I-II); (II) be aged 45 to 70; (III) have correctly followed the doctor's instructions and have an accurate understanding of the pain score; and (IV) have provided informed consent. Patients were excluded from the study if they met any of the following exclusion criteria: (I) had an organic disease; (II) had blood diseases and coagulation dysfunction; (III) were allergic to anesthetics; (IV) were infected at the puncture site; (V) had central or peripheral nervous system diseases; and/or (VI) had a long-term history of receiving analgesic and sedative medications. This article was a two-parallel test, mainly used two different treatment options to detect the impact on patients. Allocation ratio is closed to 1:1.

The patients were divided into 2 groups using the random number method, including control group $(n=57)$ and observation group $(\mathrm{n}=58)$. There was no difference in the basic data between the 2 groups $(\mathrm{P}>0.05)$, and the 2 groups were comparable (see Table 1).

\section{Study method}

The control group was given simple general anesthesia (and were required to fast for 8 hours and not drink for 2 hours before the operation). After entering the room, the upper extremity venous access was established, vital signs were monitored, and $0.05 \mathrm{mg} / \mathrm{kg}$ of midazolam (Jilin Jinsheng Pharmaceutical Co., Ltd., National Medicine Zhunzi H20193337), $1.50 \mathrm{mg} / \mathrm{kg}$ of propofol (Guangdong Jiabo Pharmaceutical Co., Ltd., China National Medicine Zhun H20051843), $4 \mu \mathrm{g} / \mathrm{kg}$ of fentanyl (Yichang Renfu Pharmaceutical Co., Ltd., National Medicine Standard H20203055), and $0.15 \mathrm{mg} / \mathrm{kg}$ of cisatracurium [Shanghai Dongying (Jiangsu) Pharmaceutical Co., Ltd., National Medicine Standard H20133373]were sequentially injected intravenously to induce anesthesia. After 3 minutes, a tracheal intubation was performed, and the anesthesia machine was connected to positive pressure ventilation. During the operation, propofol (4-6 mg/kg/h), remifentanil $(0.15-0.20 \mu \mathrm{g} / \mathrm{kg} / \mathrm{h})$, and cis-atracurium $(0.10-0.15 \mathrm{mg} / \mathrm{kg} / \mathrm{h})$ were continuously injected intravenously to maintain the depth of anesthesia and muscle relaxation, and the bispectral index (BIS) was 45-60. After surgery, patient-controlled intravenous analgesia was administered, and $2 \mu \mathrm{g} / \mathrm{kg}$ of Sufentanil (Yichang Renfu Pharmaceutical Co., Ltd., National Medicine Standard H20054172), $0.30 \mathrm{mg} / \mathrm{kg}$ of Dezocine 
Table 1 General information

\begin{tabular}{lccccc}
\hline \multirow{2}{*}{ Group } & Age $($ year $)$ & BMl $\left(\mathrm{kg} / \mathrm{m}^{2}\right)$ & Timeofoperation & \multicolumn{2}{c}{ ASA, $\mathrm{n}(\%)$} \\
\cline { 5 - 6 } & & & $(\mathrm{min})$ & I grape & II grape \\
\hline Observation group $(\mathrm{n}=58)$ & $55.78 \pm 7.13$ & $22.70 \pm 2.56$ & $127.63 \pm 10.44$ & $38(65.52)$ & $20(34.48)$ \\
Control group $(\mathrm{n}=57)$ & $56.27 \pm 7.20$ & $22.58 \pm 2.50$ & $127.46 \pm 10.38$ & $40(70.18)$ & $17(29.82)$ \\
$\chi^{2} / \mathrm{t}$ & 0.367 & 0.254 & 0.088 & 0.286 \\
$P$ & 0.715 & 0.800 & 0.930 & 0.593 \\
\hline
\end{tabular}

$P$ value, probability; $\chi^{2}$-test, Chi-square test.

(Nanjing Youke Pharmaceutical Co., Ltd., National Medicine Standard H20193318), $30 \mathrm{mg}$ of A Zasetron (Shanghai Xinyi Jinzhu Pharmaceutical Co., Ltd., Zhunzi H20193326), and up to $250 \mathrm{~mL}$ of normal saline was injected into the analgesic pump. The self-controlled analgesia dose was $3 \mathrm{~mL}$, and the lock time was $15 \mathrm{~min}$.

The observation group was given TTP-PECS block combined with propofol anesthesia. In relation to PECS, the patient was placed in the supine position with the arm abducted on the surgical side. After disinfecting the drape, an ultrasound-guided PECSII block was perfumed. The ultrasound probe was positioned sagittally to scan the middle and outer $1 / 3$ of the subclavian from the inside up and down. At the level of the third and fourth intercostals of the anterior axillary line, the pectoralis major, pectoralis minor, and serratus anterior muscles were identified and the needle was inserted using the planar technique. The local anesthetic ( $20 \mathrm{~mL}$ of $0.33 \%$ ropivacaine) was injected between the pectoralis minor muscle and the serratus anterior muscle. At the same time, $10 \mathrm{~mL}$ of $0.33 \%$ ropivacaine was injected between the pectoralis major and pectoralis minor muscles. In relation to the TTP, the probe was placed at the level of the fourth and fifth ribs next to the sternum on the surgical side. After distinguishing the intercostal muscles, internal thoracic arteries and veins, and transversus pectoralis, the needle was inserted from the outside to the inside. When it reached between the internal intercostal muscle and the transverse pectoralis muscle, it was drawn back, and local anesthetic $(15 \mathrm{~mL}$ of $0.33 \%$ ropivacaine) was injected.

\section{Observation indicators}

The observation indicators comprised: (I) pain. The visual analogue scoring (VAS) method was used to assess the degree of pain (9). Under this method, 0 point indicates no pain, $\leq 3$ points indicate slight pain, 4-6 points indicate pain affecting sleep, and $7-10$ points indicate unbearable pain; (II) hemodynamic factors. The levels of heart rate (HR), mean arterial pressure (MAP) at T0, T1, T2, and T3 were measured by multifunctional monitors; (III) stress. $3 \mathrm{~mL}$ of venous blood was collected for T0, T1, $\mathrm{T} 2$, and T3, centrifuged to pellet the cells, and the levels of blood glucose (GLU), epinephrine (E), cortisol (Cor) were measured by an automatic biochemical analyzer; (IV) cellular immune function. Cluster of differentiation (CD) $3^{+}$, $\mathrm{CD}^{+}, \mathrm{CD}^{+}, \mathrm{CD}^{+} / \mathrm{CD}^{+}$, and natural killer (NK) cells were detected by flow cytometry (Partec Pas, Germany); and $(\mathrm{V})$ wake-up time and the incidence of adverse reactions. "(I)", "(II)", “(III)” are the primary endpoints and "(IV)", "(V)" are the secondary endpoints. These were observed and recorded for the 2 groups.

\section{Statistical analysis}

6SPSS20.0 software was used to process the data. The count data are expressed in percentages (\%), and $\chi^{2}$ tests were performed. The measurement data are expressed as $(\bar{x} \pm s)$, and $t$-tests were performed. Repeated measurement variance analyses were used to compare the different time points. A $\mathrm{P}<0.05$ indicated that the difference was statistically significant.

\section{Results}

\section{Comparison of age, BMI, time of operation and ASA between the 2 groups}

The patients were divided into 2 groups using the random number method. There was no difference age, BMI, timeofoperation and ASA between the 2 groups $(\mathrm{P}>0.05)$, and the 2 groups were comparable (see Table 1 and Figure 1). 


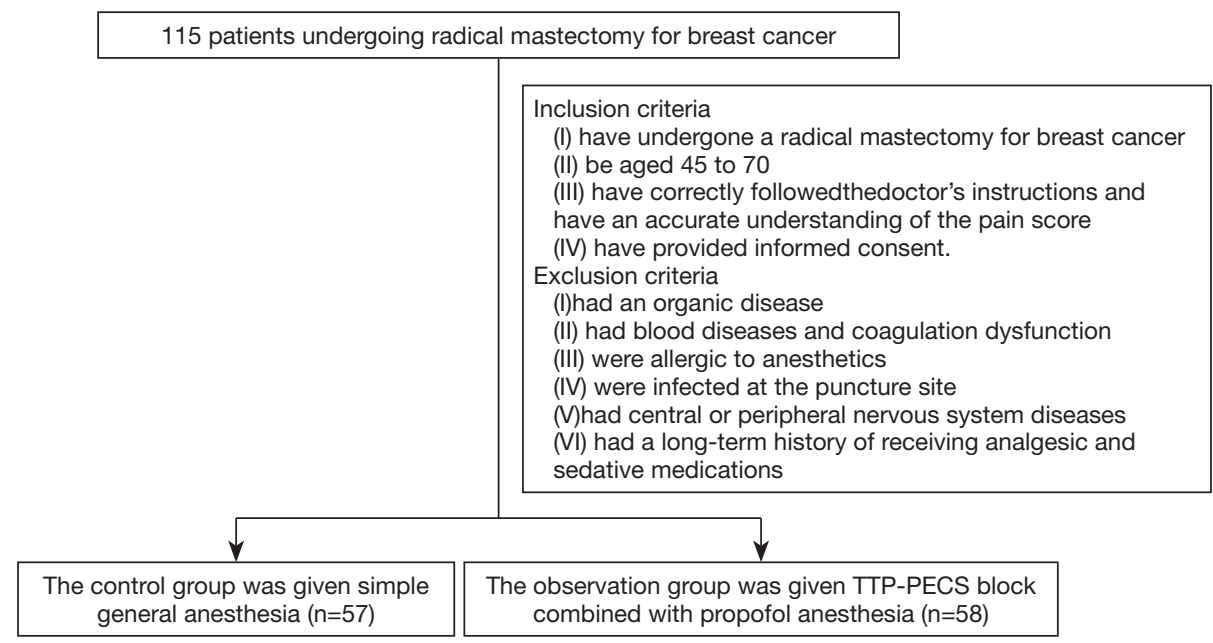

Figure 1 Screening and grouping of patients.

Table 2 Comparison of wake-up times between the 2 groups $(\bar{x} \pm s)$

\begin{tabular}{lccc}
\hline Group & Recovery of spontaneous breathing $(\mathrm{min})$ & Full wakefulness $(\mathrm{min})$ & Removal of the tracheal tube $(\mathrm{d})$ \\
\hline Observation group $(\mathrm{n}=58)$ & $5.80 \pm 1.41$ & $15.60 \pm 3.54$ & $3.14 \pm 0.10$ \\
Control group $(\mathrm{n}=57)$ & $13.75 \pm 3.12$ & $26.27 \pm 5.18$ & $4.03 \pm 0.25$ \\
$\mathrm{t}$ & 17.658 & 12.916 & 25.144 \\
$\mathrm{P}$ & $<0.001$ & $<0.001$ & $<0.001$ \\
\hline
\end{tabular}

$P$ value, probability; $t$-test, Student's $t$-test.

Table 3 Comparison of VAS scores between the 2 groups $(\bar{x} \pm s)$

\begin{tabular}{|c|c|c|c|c|}
\hline Group & $2 \mathrm{~h}$ after operation & $8 \mathrm{~h}$ after operation & $12 \mathrm{~h}$ after operation & $24 \mathrm{~h}$ after operation \\
\hline Control group $(n=57)$ & $2.30 \pm 0.64$ & $3.05 \pm 0.77$ & $2.75 \pm 0.60$ & $2.04 \pm 0.30$ \\
\hline $\mathrm{F}$ & \multicolumn{4}{|c|}{$F_{\text {interblock }}=16.710, F_{\text {differentimepoints }}=643.500, F_{\text {interaction }}=10.250$} \\
\hline$P$ & \multicolumn{4}{|c|}{$<0.001$} \\
\hline
\end{tabular}

$\mathrm{P}$ value, probability; $\mathrm{F}$ value, oscillator strength.

\section{Comparison of wake-up times between the 2 groups}

The times it took patients in the observation group to recover spontaneous breathing, achieve full wakefulness, and remove the tracheal tube were shorter than those of the control group $(\mathrm{P}<0.05$; see Table 2$)$.

\section{Comparison of VAS scores between the 2 groups}

The VAS scores of the observation group at 2, 8, 12, and
$24 \mathrm{~h}$ after operation were lower than those of the control group $(\mathrm{P}<0.05$; see Table 3$)$.

\section{Comparison of hemodynamic indicators between the 2 groups}

There was no difference in HR and MAP between the 2 groups at T0 $(\mathrm{P}>0.05)$. The MAP and HR at $\mathrm{T} 1, \mathrm{~T} 2$, and $\mathrm{T} 3$ of the observation group were lower than those of the 
Table 4 Comparison of hemodynamic indicators between the 2 groups $(\bar{x} \pm s)$

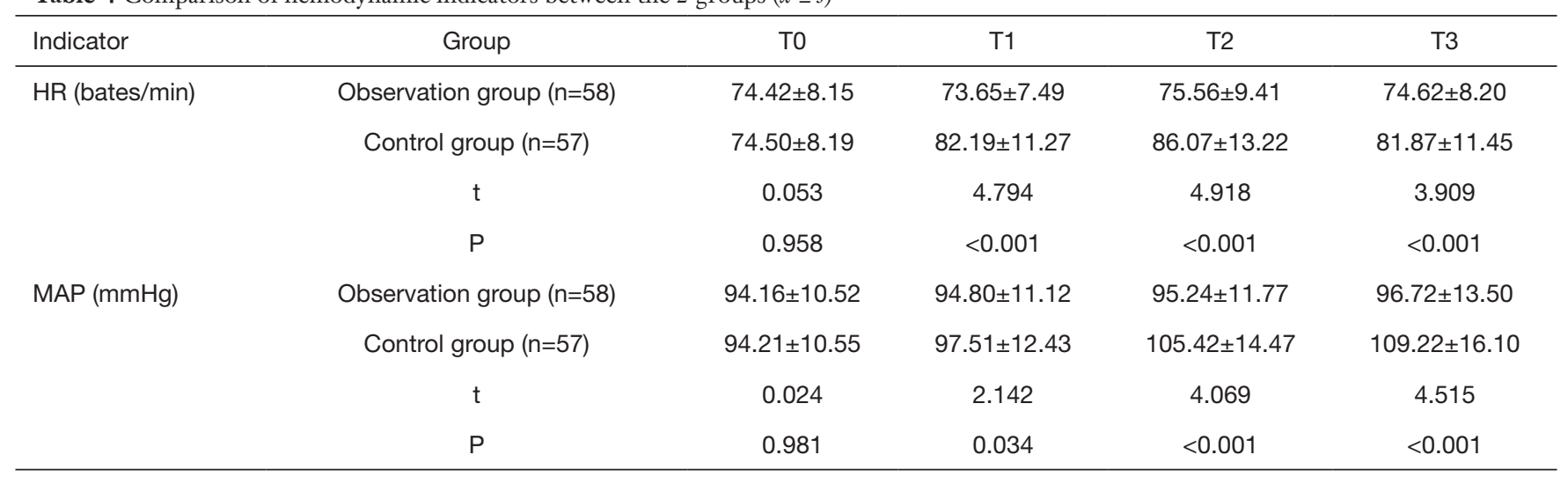

$P$ value, probability; $t$-test, Student's $t$-test.

Table 5 Comparison of stress levels between the 2 groups $(\bar{x} \pm s)$

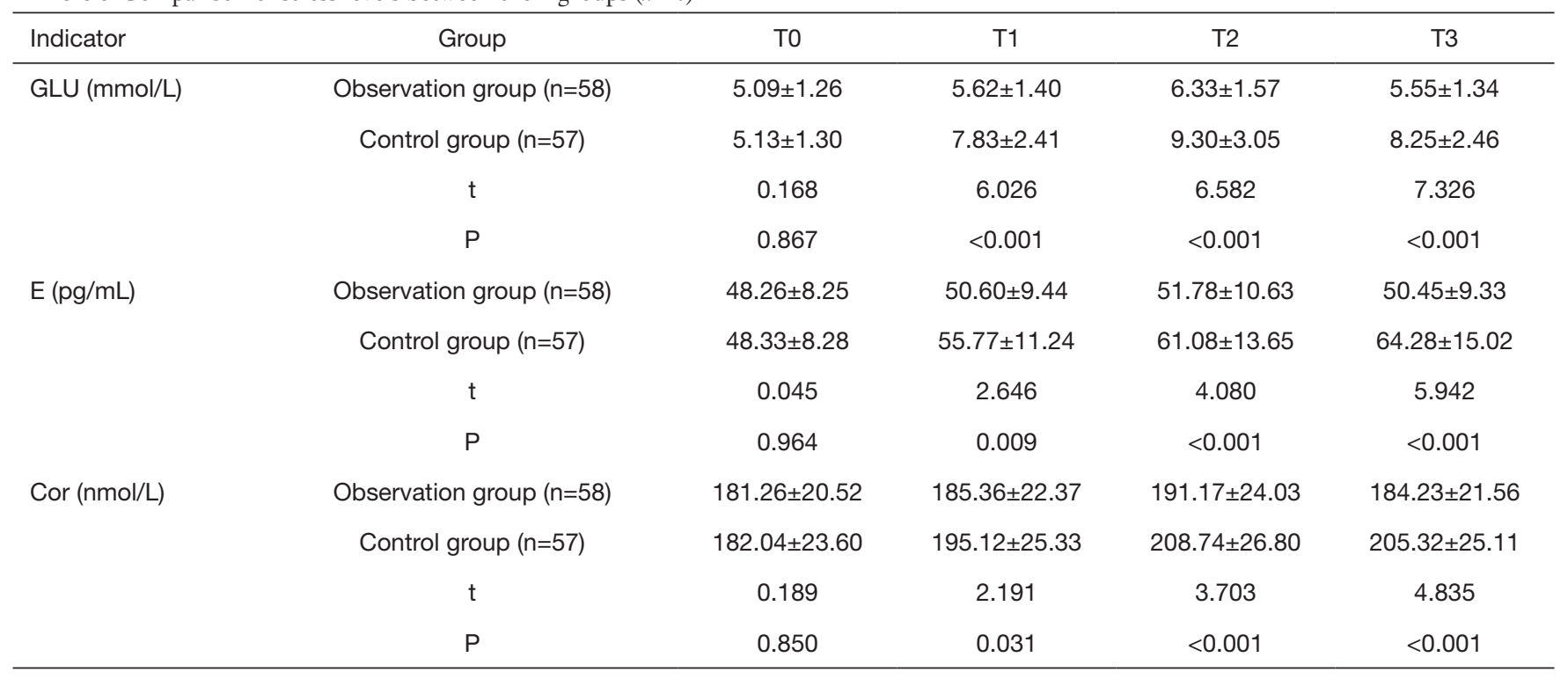

$P$ value, probability; $t$-test, Student's $t$-test.

control group $(\mathrm{P}<0.05$; see Table 4).

\section{Comparison of stress levels between the 2 groups}

There was no difference in serum GLU, E, and Cor levels between the 2 groups at T0 $(\mathrm{P}>0.05)$. Serum GLU, E, and Cor levels at T1, T2, and T3 in the observation group were decreased than those in the control group $(\mathrm{P}<0.05$; see Table 5).

\section{Comparison of cellular immune function between the 2 groups}

There was no difference in the $\mathrm{CD}^{+}, \mathrm{CD}^{+}, \mathrm{CD}^{+}, \mathrm{CD}^{+} \%$ $\mathrm{CD} 8^{+}$, and $\mathrm{NK}$ cells between the 2 groups at $\mathrm{T} 0(\mathrm{P}>0.05)$. The $\mathrm{CD}^{+}, \mathrm{CD}^{+}$, and $\mathrm{CD}^{+} / \mathrm{CD}^{+}$cells in the observation group were higher compared to those in the control group at $\mathrm{T} 1, \mathrm{~T} 2$, and $\mathrm{T} 3(\mathrm{P}<0.05)$. There was no difference in the $\mathrm{CD} 8^{+}$and NK cells between the 2 groups at $\mathrm{T} 1, \mathrm{~T} 2$, and $\mathrm{T} 3$ 
Table 6 Comparison of cellular immune function between the 2 groups $(\bar{x} \pm s)$

\begin{tabular}{|c|c|c|c|c|c|}
\hline Indicator & Group & T0 & T1 & T2 & T3 \\
\hline $\mathrm{CD}^{+}$ & Control group $(n=57)$ & $84.12 \pm 12.65$ & $71.06 \pm 6.52^{\#}$ & $74.36 \pm 7.98^{\#}$ & $77.44 \pm 9.36^{\#}$ \\
\hline \multirow[t]{2}{*}{$\mathrm{CD}^{+}$} & Observation group $(\mathrm{n}=58)$ & $47.25 \pm 9.63$ & $42.63 \pm 7.16^{\star \#}$ & $41.86 \pm 6.87^{\star \#}$ & $45.74 \pm 8.79^{\star}$ \\
\hline & Control group $(n=57)$ & $46.91 \pm 9.55$ & $37.74 \pm 5.28^{\#}$ & $38.50 \pm 5.71^{\#}$ & $41.52 \pm 6.70^{\#}$ \\
\hline $\mathrm{CD}^{+}$ & Control group $(n=57)$ & $31.01 \pm 6.62$ & $30.51 \pm 6.53$ & $29.70 \pm 5.43$ & $27.96 \pm 5.14^{\#}$ \\
\hline \multirow[t]{2}{*}{$\mathrm{CD}^{+} / \mathrm{CD}^{+}$} & Observation group $(n=58)$ & $1.61 \pm 0.23$ & $1.36 \pm 0.17^{\star \#}$ & $1.38 \pm 0.20^{\star \#}$ & $1.57 \pm 0.31^{*}$ \\
\hline & Control group $(n=57)$ & $1.63 \pm 0.25$ & $1.20 \pm 0.10^{\#}$ & $1.30 \pm 0.16^{\#}$ & $1.45 \pm 0.28^{\#}$ \\
\hline NK cell & Observation group $(n=58)$ & $16.10 \pm 3.59$ & $13.80 \pm 2.77^{\#}$ & $13.95 \pm 2.83^{\#}$ & $15.69 \pm 4.02$ \\
\hline
\end{tabular}

Compared with the control group, ${ }^{*} \mathrm{P}<0.05$; compared with T0 group, ${ }^{*} \mathrm{P}<0.05$.

Table 7 Comparison of the incidence of adverse reactions between the 2 groups [ $\mathrm{n}(\%)]$

\begin{tabular}{|c|c|c|c|c|c|c|}
\hline Group & Respiratorydepression & Nauseaandvomiting & Hypotension & Bradycardia & Uroschesis & Total complications \\
\hline Control group $(n=57)$ & $2(3.51)$ & $4(7.02)$ & $3(5.26)$ & $2(3.51)$ & $3(5.269)$ & $14(24.56)$ \\
\hline$\chi^{2}$ & & & & & & 6.166 \\
\hline$P$ & & & & & & 0.013 \\
\hline
\end{tabular}

$\mathrm{P}$ value, probability; $\chi^{2}$-test, Chi-square test.

( $\mathrm{P}>0.05$; see Table 6).

\section{Comparison of the incidence of adverse reactions between the 2 groups}

The incidence of adverse reactions in the observation group was lower than that in the control group (8.62\% vs. $24.56 \%$; $\mathrm{P}<0.05$; see Table 7).

\section{Discussion}

In recent years, the incidence of breast cancer has been on the rise (10). According to reports, breast cancer accounts for $7-10 \%$ of systemic malignant tumors, and is the most common tumor among females (10). Surgery is an effective means of treatment, but it is traumatic, the operation area involves extensive nerves, and the movement of the shoulder joint is limited after surgery (11). Additionally, postoperative hematoma and accumulated fluid pressure stimulate the nerves, which can lead to an increased HR, increased blood pressure, and increased myocardial oxygen consumption, which in turn can trigger postoperative cardiovascular events and severely affect a patient's postoperative recovery. Thus, improving perioperative pain management is crucial (12).

General anesthesia is a commonly used in radical mastectomy for breast cancer, but it cannot completely block the conduction of peripheral stimulation to the central nervous system. Additionally, the large amount of anesthetics used in the operation can cause symptoms, such as respiratory de pression, nausea and vomiting, and an adverse prognosis $(13,14)$. With the continuous improvement of anesthesia technology, TTP-PECS block is gradually being applied in clinical practice. It is a new type of peripheral fascial nerve block. By injecting anesthetics into the muscle space of the chest wall, the thoracic nerve depends on the diffusion of the drug to achieve an analgesic effect (15). PECS block can block the intercostal 
nerve, the intercostal brachial nerve, the lateral cutaneous branch of the intercostal nerve, the medial cutaneous nerve of the arm and forearm, the long thoracic nerve, and the thoracic dorsal nerve; however, it cannot block the anterior cutaneous branch of the intercostal nerve (16). Conversely, TTP block is mainly used to block the anterior cutaneous branch of the intercostal nerve that dominates the medial breast areal (17). Thus, the combined analgesic effect of the 2 is significant (17). Propofol has a circulatory inhibitory function that can counteract the excitement of intraoperative sympathetic nerves by inhibiting myocardial contraction and dilating peripheral blood vessels (18).

The present study showed that the observation group's recovery of spontaneous breathing, full wakefulness, and tracheal tube removal times were shorter than those of the control group. Thus, the TTP-PECS block combined with propofol anesthesia appears to shorten the recovery time of patients undergoing a radical mastectomy. This study also showed that the VAS scores of the observation group at 2, 8,12 , and $24 \mathrm{~h}$ after operation were lower than those of the control group. Thus, the TTP-PECS block combined with propofol anesthesia appears to have a better analgesic effect than general anesthesia and can prolong the drug effect. TTP-PECS block injects anesthetics into the fascia to form a relatively closed space, which causes the anesthetic and nerve receptors to bind for a long time. The study also found that the MAP and HR of the observation group at T1, T2, and T3 were lower than those of the control group, which is consistent with the findings of Zhao et al. (19) that the TTP-PECS block combined with propofol anesthesia can stabilize blood flow level. If TTP-PECS can completely block the afferent nerves in the surgical operation area, the stimulation caused by the operation process will not cause pain signal changes and afferent nerve conduction. Thus, there is a stable depth of anesthesia during the operation, and hemodynamic fluctuations are small. However, surgical injury, the application of anesthetics, and postoperative pain can produce a strong stress response, which is manifested by increased blood sugar and adrenaline, and sympathetic nerve excitement. This study found that the levels of GLU, $\mathrm{E}$, and Cor in the observation group at T1, T2, and T3 were lower than those in the control group. Thus, TTPPECS block combined with propofol appears to attenuate the stress response. This is related to the strong suppression of sympathetic nerves caused by TTP-PECS block combined with propofol anesthesia.

It is currently believed that $\mathrm{T}$ lymphocytes play an important role in the body's anti-tumor immunity.
Notably, $\mathrm{CD}^{+}$has immune surveillance and humoral regulation immune functions, $\mathrm{CD}^{+}$can assist the body's immune function, promote immune response, and induce hypersensitivity, $\mathrm{CD} 8^{+}$can inhibit antibody synthesis and secretion, and $\mathrm{CD} 4^{+} / \mathrm{CD}^{+}$is an indicator of disease severity and poor prognosis. NK cells have extensive killing tumor cells (20). This study found that $\mathrm{CD}^{+}, \mathrm{CD}^{+}$, and $\mathrm{CD}^{+} /$ $\mathrm{CD} 8^{+}$cells at $\mathrm{T} 1, \mathrm{~T} 2$, and $\mathrm{T} 3$ in the observation group were increased compared to those in the control group. Thus, the TTP-PECS block combined with propofol anesthesia has a lower degree of immunosuppression, which may be related to hemodynamics and stress responses.

In addition, this study also found that the incidence of adverse reactions in the observation group was lower than that in the control group (8.62\% vs. $24.56 \%)$. Thus, TTPPECS block combined with propofol anesthesia appears to be safe and beneficial in promoting the prognosis of patients. TTP-PECS block combined with propofol anesthesia can reduce the amount of anesthetic required, and the anesthesia recovery time is shorter, which is conducive to the recovery of organ function and can effectively reduce the occurrence of complications.

In summary, the TTP-PECS block combined with propofol anesthesia can alleviate the pain of patients undergoing radical mastectomy, stabilize hemodynamics, reduce stress responses, and has a low degree of suppression of cellular immune function. Thus, it is worthy of promotion and application.

\section{Acknowledgments}

Funding: None.

\section{Footnote}

Reporting Checklist: The authors have completed the CONSORT reporting checklist. Available at https://dx.doi. org/10.21037/gs-21-343

Trial Protocol: Available at https://dx.doi.org/10.21037/gs21-343

Data Sharing Statement: Available at https://dx.doi. org/10.21037/gs-21-343

Conflicts of Interest: All authors have completed the ICMJE uniform disclosure form (available at https://dx.doi. org/10.21037/gs-21-343). The authors have no conflicts of 
interest to declare.

Ethical Statement: The authors are accountable for all aspects of the work in ensuring that questions related to the accuracy or integrity of any part of the work are appropriately investigated and resolved. The study was conducted in accordance with the Declaration of Helsinki (as revised in 2013). This study was approved by the Sichuan Provincial People's Hospital, University of Electronic Science and Technology of China (No. 20181205). All patients agreed to participate in this study and signed an informed consent form.

Open Access Statement: This is an Open Access article distributed in accordance with the Creative Commons Attribution-NonCommercial-NoDerivs 4.0 International License (CC BY-NC-ND 4.0), which permits the noncommercial replication and distribution of the article with the strict proviso that no changes or edits are made and the original work is properly cited (including links to both the formal publication through the relevant DOI and the license). See: https://creativecommons.org/licenses/by-nc-nd/4.0/.

\section{References}

1. Goutham VVN, Venkata GM, Vandana M, et al. A prospective study on the comparison of general anesthesia and tea (thoracic epidural anesthesia) for perioperative outcomes in patients undergoing modified radical mastectomy. Int J Res Pharmaceuti Sci 2020;11:7665-9.

2. Zhu L, Zhang Z, Zhang S, et al. A novel balanced anesthesia shortens time to emergence in patients undergoing modified radical mastectomy: a randomized prospective trial. Ann Palliat Med 2021;10:2439-47.

3. Ibrahim ES, Sultan WA. Adenosine or Magnesium Sulphate as Adjuvants for Pectoral Nerves Block in Modified Radical Mastectomy: A Randomized Controlled Tria. Open J Anesthesiol 2018;8:159-71.

4. Gupta K, Srikanth K, Girdhar KK, et al. Analgesic efficacy of ultrasound-guided paravertebral block versus serratus plane block for modified radical mastectomy: A randomised, controlled trial. Indian J Anaesth 2017;61:381-6.

5. Abu Elyazed MM, Abdelghany MS, Mostafa SF. The Analgesic Efficacy of Pecto-Intercostal Fascial Block Combined with Pectoral Nerve Block in Modified Radical Mastectomy: A Prospective Randomized Trial. Pain Physician 2020;23:485-93.
6. Jin Z, Li R, Gan TJ, et al. Pectoral Nerve (PECs) block for postoperative analgesia-a systematic review and meta-analysis with trial sequential analysis. Int J Physiol Pathophysiol Pharmacol 2020;12:40-50.

7. Teixeira LG, Pujol DM, Pazzim AF, et al. Combination of Transversus abdominis plane block and Serratus plane block anesthesia in dogs submitted to masctetomy. Pesq. vet.bras 2018;38:315-9.

8. Du H, Liu X, Li F, et al. Anesthetic effect of ultrasoundguided multiple-nerve blockade in modified radical mastectomy in patients with breast cancer. Medicine (Baltimore) 2021;100:e24786.

9. Shukla RH, Nemade SV, Shinde KJ. Comparison of visual analogue scale (VAS) and the Nasal Obstruction Symptom Evaluation (NOSE) score in evaluation of post septoplasty patients. World J Otorhinolaryngol Head Neck Surg 2020;6:53-8.

10. Pan H, Tao J, Qian M, et al. Concordance assessment of Watson for Oncology in breast cancer chemotherapy: first China experience. Transl Cancer Res 2019;8:389-401.

11. Yang XH, Bai Q, Lv MM, et al. Effect of dexmedetomidine on immune function of patients undergoing radical mastectomy: a double blind and placebo control study. Eur Rev Med Pharmacol Sci 2017;21:1112-6.

12. Zishan MS, Ali T, Rafiq S, et al. Role of para vertebral blocks afte unilateral modified radical mastectomy for breast cancer. Med Forum Monthly 2019;30:15-9.

13. Wu G, Fu G, Zhang L, et al. Effects of neoadjuvant chemotherapy on the depth of total intravenous anesthesia in patients with breast cancer undergoing unilateral modified radical mastectomy: A prospective observational study. Medicine (Baltimore) 2018;97:e13776.

14. Goutham VVN, VenkataGM, Vandana M, et al. A prospective study on the comparison of general anesthesia and tea (thoracic epidural anesthesia) for perioperative outcomes in patients undergoing modified radical mastectomy. Int J Res Pharmaceutical Sci 2020;11:7665-9.

15. Bakeer AH, Kamel KM, Abdelgalil AS, et al. Modified Pectoral Nerve Block versus Serratus Block for Analgesia Following Modified Radical Mastectomy: A Randomized Controlled Trial. J Pain Res 2020;13:1769-75.

16. Hara E, Ueshima H, Tanaka N, et al. Pectoral Nerves (PECS) Block Is Effective for Motor Function Recovery in the Early Postoperative Period after Breast Cancer Surgery. Open J Anesthesiol 2017;7:351-5.

17. Conway AM, Salih Z, Papaxoinis G, et al. Significance of blood neutrophil-to-lymphocyte ratio for prognostic stratification of patients with gastroesophageal junction 
adenocarcinoma in the era of the 8th edition of the American Joint Committee on Cancer (AJCC8) staging. Med Oncol 2017;34:116-34.

18. Guo F, Chen H, Cai X, et al. Effects of dexmedetomidine as an adjuvant in thoracic paravertebral block on EC50 of propofol for successful laryngeal mask insertion: a randomized controlled trial. Ann Transl Med 2020;8:1480.

19. Zhao Y, Shao A, Feng S, et al. Analgesic effect of ultrasound-guided thoracic wall nerve block and thoracic paravertebral nerve block in modified radical mastectomy of breast cancer. J Clin Anesthesiol 2020;36:58-62 .

20. Geng MQ, Chen X, Lu L, et al. Effects of different anesthesia methods on immune function, oxidative stress and related cytokine levels in elderly lung cancer patients undergoing radical operation. J hainan Med University 2018;24:62-6.

(English Language Editor: L. Huleatt)

Cite this article as: Li J, Lyu Q, Su W, Li M, Du Y, Hu Y. A randomised trial: effects of different anesthesia methods on early perioperative pain sensitivity and cellular immune function in patients undergoing radical mastectomy. Gland Surg 2021;10(7):2246-2254. doi: 10.21037/gs-21-343 